A Lithospheric Attenuation Model of North America

M. E. Pasyanos

May 13, 2013

Bulletin of the Seismological Society of America 
This document was prepared as an account of work sponsored by an agency of the United States government. Neither the United States government nor Lawrence Livermore National Security, LLC, nor any of their employees makes any warranty, expressed or implied, or assumes any legal liability or responsibility for the accuracy, completeness, or usefulness of any information, apparatus, product, or process disclosed, or represents that its use would not infringe privately owned rights. Reference herein to any specific commercial product, process, or service by trade name, trademark, manufacturer, or otherwise does not necessarily constitute or imply its endorsement, recommendation, or favoring by the United States government or Lawrence Livermore National Security, LLC. The views and opinions of authors expressed herein do not necessarily state or reflect those of the United States government or Lawrence Livermore National Security, LLC, and shall not be used for advertising or product endorsement purposes. 


\title{
A Lithospheric Attenuation Model of North America
}

\author{
Michael E. Pasyanos \\ Lawrence Livermore National Laboratory, 7000 East Avenue, L-046, P.O. \\ Box 808, Livermore, California 94551
}

\begin{abstract}
Recent moderate-sized, but strongly-felt, earthquakes in eastern and central North America have highlighted the important role of the earth's attenuation structure in estimating and predicting local and regional ground motions. Over the past several years, we have been developing methods to use the amplitudes of regional phases $\mathrm{Pn}, \mathrm{Pg}, \mathrm{Sn}$, and $\mathrm{Lg}$ to invert for the crust and upper mantle attenuation structure in Eurasia, and have recently started transporting the methodology to North America. We now have path coverage for most of North America, including Canada, the United States, Mexico, and portions of the Caribbean, with the best coverage in the United States. After describing the development of the model, we will discuss the results in the context of the tectonics of the region, most notably the large differences between western North America and areas east of the Rockies. We will then demonstrate the use of the model in a number of applications including estimating reliable moment magnitudes for the Wells, $\mathrm{NV}$ earthquake sequence, the use of the models in strong ground motion prediction for the Mineral, VA mainshock, and in both discriminating and estimating explosion characteristics (depth, yield) of events at the Nevada Test Site.
\end{abstract}




\section{Introduction}

The August 23, 2011 Mineral, VA earthquake was only a moderate-sized $\left(\mathrm{M}_{\mathrm{w}}\right.$ 5.8) earthquake, but was widely felt throughout the east coast of North America. As reported in the popular media such as the New York Times (New York Times, 2011), it was felt more strongly and over a wider region than similar sized earthquakes in western North America. The event highlighted the important role that the earth's seismic attenuation structure has in estimating and predicting ground motions.

Over the past several years, we have been developing methodologies to use the amplitudes of regional phases to invert for crust and upper mantle attenuation structure. In a series of papers, we have developed the methodology using the Lg phase (Pasyanos et al., 2009a), extended the method to use amplitudes of the Pn, Pg, Sn, and $\mathrm{Lg}$ in a multiphase inversion method (Pasyanos et al., 2009b), then used the model in a series of applications including seismic discrimination between earthquakes and explosions (Pasyanos and Walter, 2009; Pasyanos et al., 2012a), moment magnitude estimation (Pasyanos, 2010), and in strong ground motion predictions for seismic hazard (Pasyanos, 2011). In a further extension of the model, we used the attenuation model in the analysis of the yield and depth of the 2006 and 2009 DPRK nuclear tests (Pasyanos et al., 2012b). The geographic area for these studies was initially the Middle East, but then expanded to include other portions of broader Eurasia including South Asia, Central Asia, and East Asia.

Here, we have transported the methodology from Eurasia to North America (Figure 1). We have used a set of recent earthquakes in the eastern and central United States, along with more commonly occurring events in the western United States, which were well-recorded by national and regional networks in North America. We use these events to make thousands of local and regional amplitude measurements, which we use to create an attenuation model of the crust and upper mantle.

After describing the development of the model, we will discuss the results in the context of North America tectonics. We will then demonstrate the use of the model in a number of applications. First, we will use the model in the estimation of moment magnitudes using regional phase amplitudes. We will do so by calculating magnitudes for a range of events from the Wells, NV earthquake sequence and compare them to moment estimates made using regional waveform modeling. Secondly, we will demonstrate how strong ground motion estimates made using this model compare to observed ground motions for the Mineral, VA earthquake sequence. Next, we will use the model to improve our ability to discriminate earthquakes and explosions, including a large number of nuclear explosions that were conducted at the Nevada Test Site (NTS), as well as several additional explosions. Lastly, we look at how the model can be used to estimate explosion characteristics (depth, yield) of several events in different emplacement conditions, where the depth, yield, and material properties of the events are independently known. 


\section{Attenuation Model}

We have developed an attenuation model of the crust and upper mantle of North America using the multiphase amplitude inversion method (Pasyanos et al., 2009b). In most of our previous inversions, we have been in seismic regions with a lot of ambient natural seismicity, but a limited number of recording stations. Through most of North America, with the exception of the west coast and the Caribbean, we are in aseismic regions with limited seismicity. Due to the installation of national networks in the United States and Canada, coverage from global seismic networks and regional networks throughout the area, we have excellent station coverage of these regions. Even in these relatively aseismic regions, there have been a limited number of moderate sized earthquakes (e.g. Mt. Carmel, IL; Sparks, OK; Guy, AK), which are well-distributed in our study area.

These events were all well-recorded at stations in the United States Geological Survey's (USGS) Advanced National Seismic System (ANSS) Backbone network. We have further supplemented this with data from the Canadian National Seismograph Network (CNSN), as well as regional stations in the Global Seismographic Network (GSN) and other regional networks (e.g. Berkeley Digital Seismic Network, Caltech Regional Seismic Network) available through IRIS. We have supplemented these amplitude measurements with additional measurements made using data from an assembled Western United States dataset for regional seismic analysis (Walter et al., 2004). While we have made measurements for both earthquakes and explosions using this dataset, only earthquake amplitudes are included in the inversion.

For each regional (Pn, Pg, Sn, Lg) phase, a window starting with the phase arrival is selected and amplitudes are measured in a series of narrow frequency bands. At local distances, we are measuring amplitudes for just Pg and what is probably more accurately referred to as $\mathrm{Sg}$. The time-domain RMS amplitudes are then converted to pseudospectral amplitudes. Amplitudes from paths meeting the signal-to-noise criteria of preevent SNR of 2.0 and a pre-phase SNR of 1.0 are used in the inversion. The total number of amplitude measurements range from a high of about 9500 paths in the 1-2 Hz passband down to about 3700 for 6-8 Hz, with up to about 3000 unique paths (Table 1). The result is coverage of the region as shown in Figure 2. We have excellent coverage, with good ray density and crossing paths, for the whole continental United States and southern portion of Canada. Coverage is poorer in northern Canada, the Atlantic and Pacific margins, and south into Mexico and the Caribbean.

We invert the amplitude measurements using multi-phase attenuation tomography method described in Pasyanos et al. (2009b). An important aspect of the method is the use of an earthquake source model for the source term, allowing us to utilize arbitrary source models (for either earthquakes and explosions) in a forward sense to predict amplitudes. The raypaths for Pg and Lg are specified as propagating in the crust, while Pn and Sn propagate primarily though the mantle, but have crustal legs under the source and station. Using this technique, we simultaneously invert the amplitudes of $\mathrm{Pn}, \mathrm{Pg}, \mathrm{Sn}$, 
and $\mathrm{Lg}$ for event source terms, station site terms, and the lateral attenuation structure (Qp and Qs) of the crust and the upper mantle.

Attenuation maps determined from the tomography in the 2-4 Hz passband are shown in Figure 3. The four panels plot the P-wave and S-wave attenuation of the crust and upper mantle. Each panel is plotted with plate boundaries (thick black lines) and physiographic provinces (thin black lines).

The most striking feature of the attenuation model, apparent in all of the maps, is the difference in Q between areas east and west of the Rocky Mountains, with eastern North America having significantly lower attenuation. Within these broad regions, we find further variations. In the west, the Colorado Plateau is a relatively high Q feature, while the Basin and Range Province has very low $Q$ values. Although coverage is poorer, Mexico appears to be consistent with the low $Q$ values of the western U.S. In eastern and central North America, we find the lowest Q in the area of the North American craton, situated between the Rocky and Appalachian mountain ranges north of the Coastal Plain. We don't find any significant differences between the Canadian Shield and the rest of the craton. We also find lower Q values in the Coastal Plain, as compared to regions north, presumably due to the large influence of low $\mathrm{Q}$ sediments. Lastly, in the mantle Qp maps, we see low attenuation which is associated with the subducting Juan de Fuca slab. We saw a similar high Q feature associated with the Japanese slab subducting under the Korean Peninsula (Pasyanos et al., 2012b).

The study of Baqer and Mitchell (1998) uses Lg coda Q to study regional variations of $\mathrm{Lg}$ coda $\mathrm{Q}$ in the continental United States. They find broad variations with the lowest Qo (250-300) in California and western Basin \& Range, and highest Qo (650750) in the northern Appalachians and Central Lowlands. In comparison, we find much smaller scale variations in $\mathrm{Q}$ that the broad sampling of Lg coda Q cannot resolve.

In the Western United States and for the Lg phase at $1 \mathrm{~Hz}$, we can compare our results to the study of Phillips and Stead (2008) who used data from USArray to develop an Lg attenuation map. These results are most directly comparable to our crustal Qs in the 1-2 Hz passband (Figure 3a). Although there are small differences, the large trends of low Q at the coast and in the Middle Rocky Mountains and high Q in the Colorado Plateau, Sierra Nevada/Great Valley, Columbia Plateau and Northern Rocky Mountains are recovered in both models. This is an agreeable result given the greater spacing of stations in our model compared to USArray.

Inversions are performed independently at a number of frequencies, including 0.5 1, 1-2, 2-4, 4-6, and 6-8 Hz. As such, we can examine the frequency dependence of our crustal and upper mantle attenuation. Figure 4 shows Qs and Qp in the crust and upper mantle as a function of frequency at locations in several particular regions of the model: Colorado Plateau, Basin and Range, Central Lowland, and Coastal Plain. As we have found in other regions, the apparent attenuation, which itself a product of both intrinsic and scattering attenuation, often does not follow a power law, as found for the frequencydependent attenuation in the Colorado Plateau. We also find systematically lower Q 
values (higher attenuation) in the Basin and Range, and higher Q (lower attenuation) in the Central Lowlands of the Central US, where the upper mantle Qp is so high, there is almost no amplitude loss beyond geometrical spreading. This is consistent with the $\mathrm{Lg}$ attenuation results from for the Basin and Range and Central US from Erickson et al. (2004). Note as well the very low crustal Q values in portions of the Gulf of Mexico, Atlantic and Pacific Oceans that are illuminated by the crustal leg of Pn and Sn amplitudes, in the absence of observed Pg and Lg.

\section{Applications}

Having a reliable attenuation model of the crust and upper mantle allows us to more reliably predict the amplitude of regional phases, which has a number of benefits. In the following subsections, we present a series of applications which make use of our ability to better estimate regional phase amplitudes using the model, notably regional moment magnitudes, strong ground motion estimates, and explosion discrimination and analysis.

Regional Moment Magnitude

In the study of Pasyanos (2010), we demonstrated a method of estimating earthquake moment and magnitude using regional phase amplitudes that we called regional $\mathrm{M}_{\mathrm{w}}$. Rather than utilizing a particular magnitude formula, which is tied to a specific phase, frequency, and 1-D attenuation structure, this method presented a general form for using any regional phase and frequency, correcting for the geometrical spreading, lateral attenuation and site terms to derive a source term, which can be described by a seismic moment.

We wish to test this method on an earthquake sequence with many events having moment tensors solutions spanning a large magnitude range. The February 21, 2008 Wells, NV earthquake sequence was selected because it had ten moment tensor solutions determined from regional waveform modeling ranging from the $M_{w} 5.9$ mainshock to a $\mathrm{M}_{\mathrm{w}}$ of 3.6 for the smallest modeled aftershock. The regional moment tensor solutions (http://www.eas.slu.edu/eqc/eqcmt.html) are those determined from Bob Herrmann at St. Louis University using the method of Herrmann et al. (2011).

Table 2 is a list of events, along with local magnitude and moment magnitude determined from moment tensor solutions. Since a regional $\mathrm{M}_{\mathrm{w}}$ can be calculated with any arbitrary combination of calibrated phases and frequencies, we have limited ourselves to four specific combinations for the sequence. For each event, we calculated a regional $\mathrm{M}_{\mathrm{w}}$ using 1) $\mathrm{Lg}$ in the 1-2 $\mathrm{Hz}$ passband, similar to the $\mathrm{m}_{\mathrm{b}}(\mathrm{Lg})$ magnitude of Nuttli (1973); 2) Pn in the 1-2 Hz passband, similar to the $\mathrm{m}_{\mathrm{b}}(\mathrm{Pn})$ magnitude of Everden (1967); 3) a multiphase (Pn, Pg, Sn, Lg) magnitude using all four phases in the 1-2 Hz passband; and 4) a broadband Lg magnitude using Lg amplitudes from 0.5-8 Hz.

An example for the 22 February 2008 23:27 aftershock showing a comparison of regional $\mathrm{M}_{\mathrm{w}}$ values calculated using the four methods (Figure 5a). In each case, small 
circles indicate individual values, while the colored symbol and bars show the mean and standard deviations for that formula. In this case, each of the formulas results in a magnitude estimate closer to the moment tensor method (indicated by the solid gray line) than the local magnitude (indicated by the dashed gray line). The standard deviation of broadband Lg magnitudes is significantly higher, probably indicating that the attenuation models are not as good as needed at the higher frequencies.

Figure 5b shows a comparison of $\mathrm{M}_{\mathrm{L}}$ and the regional $\mathrm{M}_{\mathrm{w}}$ values for all events in the sequence. The RMS difference between the values derived from the moment tensor solutions and all of the regional $\mathrm{M}_{\mathrm{w}}$ values $(0.13,0.19,0.15,0.28$ m.u., respectively) is less the RMS difference for $\mathrm{M}_{\mathrm{L}}(0.29$ m.u. $)$, and significantly so for the first three formulas, indicating a better estimate of earthquake magnitude. This magnitude method is particularly useful because it is easy to implement, and has the potential to determine $\mathrm{M}_{\mathrm{w}}$ values for earthquakes much smaller than can be obtained from regional waveform modeling.

\section{Strong Ground Motion}

In Pasyanos (2011), we posited that the attenuation maps could be used to improve strong ground motion estimates. Here, we test whether or not this is true. We have used the extensive dataset of strong ground motion parameters from the 23 August 2011 Mineral, VA earthquake. This event was recorded by dozens of stations up and down the east coast of the United States and Canada over a large area, and represents an ideal event to test the effect of variations in attenuation structure on strong ground motion.

Figure 6 is a map showing ground motions from the mainshock, color coded by the observed $1 \mathrm{~Hz}$ spectral acceleration (SA). Also plotted on the maps are predicted SA from the 1-D ground motion prediction equations (GMPEs) of Atkinson and Boore (2006), which is applicable for events in eastern North America (Figure 6a), and SA predicted from the attenuation model presented here (Figure 6b). Both predictions assume no site corrections. In comparison to the concentric contour lines of SA from the 1-D GMPEs, the attenuation model produces contours that are irregular and extend to longer distances to the northeast. They are particularly stunted to the southeast, where they encounter highly attenuating oceanic crust.

Figure 7 shows a comparison of observed SA for the event to predicted SA for both the 1-D GMPEs and GMPEs with laterally varying attenuation for $1 \mathrm{~Hz}$ SA. What is apparent is that the GMPE that utilizes laterally-varying attenuation does a better job at removing some of the trends between the predicted and observed motions for the 1-D equations. Even though there is a large amount of scatter in the data, the RMS misfit (calculated in log-amplitude) is reduced from 0.50 to $0.45 \log$-units. It appears that the attenuation models have the ability to improve predicted ground motions, but we will need to test this more rigorously for more events across the spectral band. We are planning on making this the subject of a separate study. 
Earthquake-explosion Discrimination and Event Analysis at NTS

Between 1951 and 1992, there were a total of 928 announced nuclear tests (828 underground) at the Nevada Test Site (NTS), what is now known as the Nevada National Security Site (USDOE, 2000). Many of these were well-recorded by regional seismic stations, including those from the LLNL seismic network, a four-station network surrounding NTS at distances from approximately 180 to $400 \mathrm{~km}$. One effective discriminant between earthquakes and explosions recorded at regional distances has been the relative ratio of $\mathrm{P}$-wave and $\mathrm{S}$-wave amplitudes at high frequencies, including a number of studies on explosions in the eastern and western U.S. (e.g. Kim et al., 1993; Walter et al., 1995; Taylor, 1996; Bottone et al., 2002). Lateral variations in attenuation, however, result in large amplitude variations of both the individual P-waves and the Swaves, hampering out ability to apply the method over broad regions.

Here, we apply the discriminant to LLNL stations KNB, ELK, MNV, and LAC, located at approximate compass points from the test site. We choose $\mathrm{Pn} / \mathrm{Lg}$ rather than $\mathrm{Pn} / \mathrm{Sn}$ to avoid using the Sn phase, which does not propagate effectively in the Basin and Range (e.g. Molnar and Oliver, 1969; Beghoul et al., 1993). Ideally, we would like the frequency to be high-enough for effective discrimination and at low-enough frequency for our model to be highly reliable. We make use of the regional attenuation model by correcting amplitudes assuming that the event is an earthquake of the specified size (magnitude) at that location. Earthquakes would therefore scatter around zero values for the discriminant, while explosions would appear to have anomalously large P-waves (large positive values of the discriminant).

Figure 8 shows the $\mathrm{Pn} / \mathrm{Lg}$ discriminant in the $4-6 \mathrm{~Hz}$ band for station $\mathrm{KNB}$ as a function of magnitude, and in map view. The raw discriminant (top panels) show large negative values (indicating Lg larger than Pn) for all events, as well as significant overlap between earthquake and explosion populations. Earthquakes in Baja California, for instance, have very high (explosion-like) P/S ratios. The middle panels show the same discriminant where a 1-D attenuation correction has been applied. This effectively corrects for the different geometrical spreading and attenuation of the two phases. The earthquake population is now zero-meaned and explosions have more positive values than earthquakes. The bottom set of panels show the discriminant with a 2-D attenuation correction and shows the least scatter in the earthquakes, as well as the greatest separation between the earthquake and explosion populations.

We can quantify the separation of the earthquake and explosion populations through the Mahalanobis distance (used in Hartse et al., 1998; Pasyanos et al., 2012a), a measure of separation of the means divided by a sum of the variances. A larger Mahalanobis distance indicates that the populations are more cleanly separated, giving better earthquake/explosion discrimination. A Mahalanobis distance can be translated into an equiprobable point (EP), which is the point where the rate of earthquakes misclassified as explosions matches the rate of explosions that are misclassified as earthquakes. A 1-D Q correction is needed to make the discriminant feasible for a range of distanes. As shown in Figure 9, using 2-D corrections improves our ability to 
discriminate earthquake and explosions. The 2-D correction makes it feasible for a broader region since it allows for lateral variations beyond a distance correction. The improvement seems to be greatest at frequencies above $4 \mathrm{~Hz}$, although we are recording fewer events (earthquakes and explosions) with both $\mathrm{P}$-wave and S-wave signals above the noise at the highest frequencies.

In previous work we developed a method of using regional waveform envelopes in a series of narrowband frequencies that span over a wide range to determine the source characteristics of seismic events (Pasyanos et al., 2012b). At these narrow bands, we model the whole waveform, including the direct regional phases and their respective codas, by propagating source models through estimated attenuation structure and calibrated coda decay parameters to build up the regional waveform envelope. In this previous study, we applied the technique to the 2006 and 2009 DPRK tests, where we estimated the yield and depth-of-burial of the two events. Although we have compared our estimates to those determined using other methods, we couldn't hope to know the true parameters for these events. However, we can test the veracity of the method by applying them to events at NTS where the yield and depths of the events have been reported. Table 3 is a list of seven explosions (six nuclear, one chemical) having a published yield and depth of burial (Springer et al., 2002; Denny, 1994; Rohrer, 1994).

Figure 10a is a plot showing regional waveform envelopes for the NonProliferation Experiment recorded at station ELK in the 2-3 Hz frequency band. The observed envelopes (shown in blue) are determined by averaging the envelopes of the two horizontal components where the individual components are deconvolved to ground velocity, narrow-band filtered, and plotted on a log-scale. Synthetic envelopes are calculated by determining the source spectra for a Mw 4.16 event and propagating the source amplitudes through the attenuation model to determine the direct phase amplitudes, then using coda calibration parameters to specify the coda decay. This is shown as the green line in Figure 10a, which has a characteristic sawtooth pattern where the Pn, Pg, Sn, and Lg regional phases arrive. Notice the low amplitudes for the Sn phase which, as noted, does not propagate well in the Basin and Range. The line may fit the Swaves for a smaller Mw value, but clearly misfits the P-waves.

Similarly, synthetic envelopes for an explosion can be calculated in the same way by propagating explosion sources through the model. We use the Mueller-Murphy Pwave explosion source model (Mueller and Murphy, 1971) where one specifies parameters of yield, depth, and source material. For the NPE, we select a tuff shot point and specify S-wave source amplitudes according to the Fisk conjecture (Fisk, 2006). A grid search is conducted where we vary the yield and depth of the explosion and calculate the RMS misfit of the log-amplitudes for each station in a number of narrow frequency bands from 1-8 Hz. The RMS misfit as a function of yield and depth is shown in Figure $\mathbf{1 0 b}$, where the star indicates the best fit $(\mathrm{RMS}=0.33)$. Also plotted on the figure are standard depth of burial lies drawn for a number of values ranging from $\mathrm{DOB}=$ $90(\mathrm{~W})^{(1 / 3)}$ to $\mathrm{DOB}=120(\mathrm{~W})^{(1 / 3)}$. Depth/yield values above and to the left of these lines are unlikely due to containment issues, and have been omitted. The resulting envelope from the best fitting explosion is shown as the red line in Figure 10a. As Figure 10b 
shows, the estimated parameters of 2 ktons at $400 \mathrm{~m}$ depth is quite close to the true value of 1.07 kton chemical yield at $390 \mathrm{~m}$ depth (Denny, 1994) which is indicated by the open circle. It is even closer to the estimated yield of 1.9 kton nuclear yield equivalent (Rohrer, 1994) which is indicated by the open diamond. This is a more appropriate comparison value since the Mueller-Murphy explosion model specifies an input nuclear yield.

We find similar results for the other events that had reported depths of burial and yields. Results are shown for a number of events in Figure 11. In all cases, we have excluded yields and depths where the scaled depth of burial is less than 90. The Atrisco event was discussed in the appendix of an earlier study using ELK only (Pasyanos et al., $2012 \mathrm{~b}$ ), but is repeated here with more stations (ELK, MNV, KNB) and with updated coda shape parameters and site transfer functions, and a finer sampling of depths and yields.

It looks like, in many cases, the depth is burial is not well defined. This is due, in part, to the tradeoffs between depth and yield in the underlying source model (Mueller and Murphy, 1971). There appears to be a tendency to run along a ridge of low misfit to deeper event depths. Fortunately, this does not seem to have a large effect on the estimated yield. There is also some concern about the broadness of the misfit. This comes, in part, from the different patterns of the misfit functions among the individual stations and frequency bands. This will likely improve as calibration of both the attenuation model and associated site terms improves.

\section{Conclusions}

We have developed an attenuation model of the crust and upper mantle for North America, which can be used to predict the amplitudes of regional phases. Predicting amplitudes can be used in magnitude estimation, strong ground motion estimation, and event discrimination and analysis. We have demonstrated the application of each of these, in turn.

The model presented here was developed rather straightforwardly using a small number of events using the well-distributed national networks. The model can be further improved by measuring amplitudes for a larger number of events. Higher resolution models could also be obtained using the Transportable Array of USArray, which has an average station spacing of $70 \mathrm{~km}$ in the United States. Similarly, the inclusion of temporary deployments such as CANOE (CAnadian NOrthwest Experiment) and CRANE (Canadian Rockies and Albert NEtwork) can improve coverage in Canada.

Improved path coverage, which should be possible given the station coverage of USArray, should allow us to achieve sufficient path coverage to allow us to use more layers in our earth model (e.g. sediments, multiple crustal layers) coupled with even more realistic ray paths which could include multipathing, and should result in improved attenuation models. 


\section{Data and Resources}

We use stations in the United States Geological Survey's (USGS) Advanced National Seismic System (ANSS) Backbone (http://earthquake.usgs.gov/monitoring/anss/) network, the Canadian National Seismograph Network (CNSN) (http://earthquakescanada.nrcan.gc.ca/stndon/), and stations in the Global Seismographic Network (GSN) (http://www.iris.edu/hq/programs/gsn) and several other networks (Berkeley Digital Seismic Network, Caltech Regional Seismic Network) available through IRIS (http://www.iris.edu). Additional data comes from an assembled Western United States dataset (Walter et al., 2004).

\section{Acknowledgements}

We thank Gail Atkinson for the strong ground motion parameters from the Mineral, VA earthquake. We thank Eric Matzel for the coda envelopes used in the event analysis section and Rengin Gok for the coda parameters used in the section. This work is prepared under the auspices of the U.S. Department of Energy by Lawrence Livermore National Laboratory (LLNL) under contract DE-AC52-07NA27344. This is LLNL contribution LLNL-JRNL-******.

\section{References}

Atkinson, G. M. and D. M. Boore (2006). Earthquake ground-motion prediction equations for eastern North America, Bull. Seismol. Soc. Am. 96, 2181-2205

Baqer, S. and B.J. Mitchell (1998). Regional variation of Lg coda Q in the continental United States and its relation to crustal structure and evolution, Pure Appl. Geophys., 153, 613-638.

Beghoul, N., M. Barazangi, and B.L. Isacks (1993). Lithospheric structure of Tibet and Western North America: Mechanisms of uplift and a comparative study, J. Geophys. Res., 98, 1997-2016.

Bottone, S., M.D. Fisk, and G.D. McCarter (2002). Regional seismic event characterization using a Bayesian formulation of simple kriging, Bull. Seism. Soc. Amer., 92. 2277-2296, doi:10.1785/0120010141.

Denny, M.D. (1994). Introduction and highlights, Proceedings of the Symposium of the Non-Proliferation Experiment (NPE): Results and implications for test ban treaties, 1-1-1-13.

Erickson, D., D.E. McNamara and H.M. Benz (2004). Frequency dependent Lg Q within the continental United States, Bull. Seism. Soc. Amer., 94, 1630-1643. 
Evernden, J. F. (1967). Magnitude determinations at regional and near-regional distances in the United States, Bull. Seismol. Soc. Am. 57, 591-639.

Fenneman, N.M., and D.W. Johnson (1946). Physiographic divisions of the conterminous U. S., United States Geological Survey, http://water.usgs.gov/lookup/getspatial?physio

Fisk, M.D. (2006). Source spectral modeling of regional P/S discriminants at nuclear test sites in China and the former Soviet Union, Bull. Seismol. Soc. Amer., 96, 23482367.

Hartse, H.E., R.A. Flores, and P.A. Johnson (1998). Correcting regional seismic discriminants for path effects in Western China, Bull. Seismol. Soc. Amer., 87, 551-568.

Herrmann, R.B., H. Benz, and C.J. Ammon (2011). Monitoring the earthquake source process in North America, Bull. Seism. Soc. Amer., 101, 2609-2625, doi: $10.1785 / 0120110095$.

Kim, W.-Y., D.W. Simpson, and P.G. Richards (1993). Discrimination of earthquakes and explosions in the eastern United States using regional high frequency data, Geophys. Res. Lett., 20, 1507-1510, doi:10.10129/93GL01267.

Molnar, P. and J. Oliver (1969). Lateral variations of attenuation in the upper mantle and discontinuities in the lithosphere, J. Geophys. Res., 74, 2648-2682.

Mueller, R.A. and J.R. Murphy (1971). Seismic characteristics of underground nuclear detonations: Part I. Seismic scaling law of underground detonations, Bull. Seism. Soc. Amer., 61, 1675-1692.

New York Times (2011). Maps of damage reports from the Virginia quake, Aug. 23, 2011, www.nytimes.com/interactive/2011/08/23/us/map-of-damage-reports-fromthe-virginia-quake.html

Nuttli, O. W. (1973). Seismic wave attenuation and magnitude relations for eastern North America, J. Geophys. Res. 78, 876-885.

Pasyanos, M.E., E.M. Matzel, W.R. Walter, and A.J. Rodgers (2009a). Broad-band Lg attenuation modeling of the Middle East, Geophys. J. Int., 177, 1166-1176, doi:10.1111/j.1365-246X.2009.04128.x.

Pasyanos, M.E., W.R. Walter, and E.M. Matzel (2009b). A simultaneous multi-phase approach to determine P-wave and S-wave attenuation of the crust and upper mantle, Bull. Seism. Soc. Amer., 99-6, 3314-3325, DOI: 10.1785/0120090061. 
Pasyanos, M.E. and W.R. Walter (2009). Improvements to regional explosion identification using attenuation models of the lithosphere, Geophys. Res. Lett., 36, L14304, doi:10.1029/2009GL038505.

Pasyanos, M.E. (2010). A general method to estimate earthquake moment and magnitude using regional phase amplitudes, Bull. Seism. Soc. Amer., 100, 1724-1732, doi: $10.1785 / 0120090363$.

Pasyanos, M.E. (2011). A case for the use of 3D attenuation models in ground-motion and seismic-hazard assessment, Bull. Seism. Soc. Amer., 101, 1965-1970, doi: $10.1785 / 0120110004$.

Pasyanos, M.E., S.R. Ford, and W.R. Walter (2012a). Testing event discrimination over broad regions using the historical Borovoye Observatory explosion dataset, Pure Appl. Geophys., DOI 10.1007/s00024-012-0591-4.

Pasyanos, M.E., W.R. Walter, and K.M. Mayeda (2012b). Exploiting regional amplitude envelopes: a case study for earthquakes and explosions in the Korean Peninsula, Bull. Seism. Soc. Amer., 102, doi: 10.1785/0120120012.

Phillips, W.S. and R.J. Stead (2008). Attenuation of Lg in the western US using the USArray, Geophys. Res. Lett., 35, L07307, doi:10.1029/2007GL032926.

Rohrer, R. (1994). Lawrence Livermore National Laboratory seismic yield determination for the NPE, Proceedings of the Symposium of the Non-Proliferation Experiment (NPE): Results and implications for test ban treaties, 6-179-6-182.

Springer, D.L., G.A. Pawloski, J.L. Ricca, R.F. Rohrer, and D.K. Smith (2002). Seismic source summary for all U.S. below-surface nuclear explosions, Bull. Seismol. Soc. Amer., 92, 1806-1840.

Taylor, S. (1996). Analysis of high-frequency $\mathrm{Pg} / \mathrm{Lg}$ ratios from NTS explosions and western U.S. earthquakes, Bull. Seism. Soc. Amer., 86. 1042-1053.

U.S. Department of Energy, Nevada Operations Office (2000). United States Nuclear Tests: July 1945 through September 1992, Department of Energy, DOE/NV-209 Rev 15.

Walter, W.R., K. Mayeda, and H.J. Patton (1995). Phase and spectral ratio discrimination between NTS earthquakes and explosions: Part 1: Empirical observations, Bull. Seism. Soc. Amer., 85, 1050-1067.

Walter, W.R., K.D. Smith, J.L. O'Boyle, T.F. Hauk, F. Ryall, S.D. Ruppert, S.C. Myers, R. Abbot, and D.A. Dodge (2004). An assembled Western United States dataset for regional seismic analysis, Lawrence Livermore National Laboratory, UCRLTR-206630. 
Figure captions

Figure 1. Study area showing topography and physiographic provinces from Fenneman and Johnson (1946). Red diamonds show locations used in Figure 4.

$(\mathrm{Ad}=$ Adirondack Province, $\mathrm{App}=$ Appalachian Plateaus province, $\mathrm{BR}=$ Blue Ridge Province, $\mathrm{C}-\mathrm{S}=$ Cascade-Sierra Mountains, $\mathrm{CP}=$ Colorado Plateau, ILP $=$ Interior Low Plateaus, MRM = Middle Rocky Mountains, NEP = New England Province, NRM = Northern Rocky Mountains, $\mathrm{Ou}=$ Ouachita Province, $\mathrm{Oz}=$ Ozark Plateaus, $\mathrm{Pac}=$ Pacific Border Province, Pie = Piedmont Province, SRM = Southern Rocky Mountains, SU = Superior Uplift, VR = Valley and Ridge Province, $\mathrm{Wy}=$ Wyoming Basin)

Figure 2. Path map of study area showing path coverage of $\mathrm{Pn}, \mathrm{Pg}, \mathrm{Sn}$, and $\mathrm{Lg}$ phases in the 1-2 Hz passband.

Figure 3. Map of lateral variations in the attenuation parameter $Q$ in North America for crustal Qs, mantle Qs, crustal Qp, and mantle Qp in the 2-4 Hz passband. Q is plotted on a logarithmic scale.

Figure 4. a) Qs vs. frequency at points in several provinces through our study area. Crustal values are shown as solid lines, while upper mantle values are shown as dashed lines. Points are shown as red diamonds on the map in Figure 1. b) Qp vs. frequency at the same set of points.

Figure 5. a) A comparison of several different regional $M_{w}$ formulas for a Wells, NV aftershock. Small circles are individual estimates, while the colored symbols and bars show the mean and standard deviations of the regional $\mathrm{M}_{\mathrm{w}}$ values. The solid gray line is the $\mathrm{M}_{\mathrm{w}}$ value from moment tensor solution and the dashed gray line is the local magnitude $\mathrm{M}_{\mathrm{L}}$. b) A comparison of regional $\mathrm{M}_{\mathrm{w}}$ to local magnitudes and moment magnitudes determined using regional waveform modeling for the events in the sequence. RMS values between $\mathrm{Mw}$ from moment tensor solutions and the four regional $\mathrm{M}_{\mathrm{w}}$ formulas and $\mathrm{M}_{\mathrm{L}}$ are indicated in the upper left corner.

Figure 6. $1 \mathrm{~Hz}$ spectral acceleration (SA) of the Mineral, VA earthquake (provided in units of g). a) Map showing $1 \mathrm{~Hz}$ SA with observed SA indicated by colored triangles, and SA predicted by Atkinson and Boore (2006) indicated by contour lines. The location of the mainshock as a star. b) Map showing $1 \mathrm{~Hz}$ SA with observed SA indicted by colored triangles and SA predicted by the attenuation model indicated by contour lines.

Figure 7. A comparison of predicted and observed SA (in g) for the Mineral, VA earthquake. The red circles indicate 1-D ground motion predictions of Atkinson and Boore (2006), while the blue circles indicate 2-D ground motion predictions from attenuation tomography. Numbers on plot indicate RMS difference in log-amplitude units. 
Figure 8. Pn/Lg discriminant at 4-6 Hz frequency recorded at station KNB showing raw data and data with 1-D and 2-D attenuation corrections. The plots on the left show $\log (\mathrm{Pn} / \mathrm{Lg})$ as a function of magnitude. Earthquakes are designated by blue circles, while explosions are designated by red stars. The plots on the right show the discriminants in map view color-coded by the discriminant value.

Figure 9. Summary of discrimination results for station KNB showing the Mahalanobis distance $\Delta^{2}$ (left axis) and equiprobable point (right axis) at $0.5-1,1-2,2-4,4-6,6-8$, and 8-10 Hz for raw amplitude ratios (red) and 1-D (yellow) and 2-D (green) path corrected amplitude ratios. Error bars are the standard deviations of the discriminant values determined using bootstrapping. Number of earthquake and explosions observed in that frequency band are provided below the passbands.

Figure 10. a) Regional waveform envelopes for the Non-Proliferation Experiment (NPE) explosion recorded at station ELK in the 2-3 Hz passband. The y-axis shows log amplitude of velocity. The envelopes determined with data from the two horizontal components are shown in blue. Synthetic envelopes for a $M_{w} 4.16$ earthquake are shown in green. Synthetic envelopes for the best-fitting explosions are shown in red. b) Misfit of the NPE explosion as a function of depth of burial and explosive yield assuming the Mueller-Murphy model, tuff shot point and the Fisk conjecture. The minimum RMS is indicated with the star. Contours of $5 \%$ and $10 \%$ above the minimum are drawn. The line shows a standard depth of burial of $90-120(\mathrm{~W})^{1 / 3}$.

Figure 11. Yield-depth estimates for a number of events at the Nevada Test Site:

Hearts, Jomada, Atrisco, Chancellor, Glencoe, and Cybar. Each figure shows misfit as a function of depth of burial and explosive yield. The minimum RMS is indicated with the star. Actual yield and depths are indicated by the open circles. 
Table 1. Number of amplitude measurements and unique paths in each frequency band.

\begin{tabular}{|l|l|l|}
\hline Frequency (Hz) & Amplitudes & Paths \\
\hline $0.5-1$ & 8520 & 2742 \\
\hline $1-2$ & 9424 & 2890 \\
\hline $2-4$ & 8859 & 2801 \\
\hline $4-6$ & 6982 & 2412 \\
\hline $6-8$ & 5857 & 2152 \\
\hline $8-10$ & 3698 & 1449 \\
\hline
\end{tabular}

Table 2. Events in the 2008 Wells, NV earthquake sequence having moment tensor solutions (Bob Herrmann, St. Louis University, personal communication; http://www.eas.slu.edu/eqc/eqc mt/MECH.NA/ )

\begin{tabular}{|l|l|l|l|l|l|l|l|l|}
\hline \hline $\begin{array}{l}\text { Origin time (GMT) } \\
\text { yyyy/mm/dd hh:mm }\end{array}$ & $\begin{array}{l}\text { Epicenter } \\
\text { Lat Lon }\end{array}$ & $\begin{array}{l}\text { Depth } \\
(\mathrm{km})\end{array}$ & $\mathrm{M}_{\mathrm{L}}$ & $\mathrm{M}_{\mathrm{w}}$ & & \multicolumn{4}{|l|}{ regional $\mathrm{M}_{\mathrm{w}}$} \\
\cline { 5 - 10 } & & & & $\begin{array}{l}\mathrm{Lg} \\
1-2\end{array}$ & $\begin{array}{l}\mathrm{Pn} \\
1-2\end{array}$ & $\begin{array}{l}\text { All } \\
1-2\end{array}$ & $\begin{array}{l}\mathrm{Lg} \\
\mathrm{BB}\end{array}$ \\
\hline $2008 / 02 / 2114: 16$ & $41.08-114.77$ & 10.0 & 6.3 & 5.88 & 5.93 & 5.68 & 5.83 & 6.15 \\
\hline $2008 / 02 / 2116: 20$ & $41.20-114.86$ & 5.0 & 4.4 & 3.89 & 4.08 & 4.11 & 4.10 & 4.13 \\
\hline $2008 / 02 / 2123: 57$ & $41.05-114.92$ & 10.0 & 4.6 & 4.61 & 4.48 & 4.56 & 4.49 & 4.51 \\
\hline $2008 / 02 / 2201: 50$ & $41.02-114.93$ & 10.0 & 3.9 & 3.86 & 4.01 & 4.07 & 4.05 & 4.20 \\
\hline $2008 / 02 / 2223: 27$ & $41.04-114.85$ & 10.0 & 4.2 & 4.32 & 4.37 & 4.30 & 4.35 & 4.46 \\
\hline $2008 / 02 / 2707: 59$ & $41.12-114.68$ & 5.0 & 4.2 & 4.12 & 4.26 & 4.24 & 4.26 & 4.58 \\
\hline $2008 / 02 / 2815: 10$ & $41.04-114.90$ & 10.0 & 3.9 & 3.98 & 3.93 & 3.95 & 3.93 & 4.02 \\
\hline $2008 / 03 / 1516: 22$ & $41.09-114.92$ & 10.0 & 3.3 & 3.57 & 3.64 & 3.87 & 3.69 & 3.58 \\
\hline $2008 / 04 / 0113: 16$ & $41.22-114.83$ & 7.6 & 4.2 & 4.12 & 4.32 & 4.27 & 4.31 & 4.59 \\
\hline $2008 / 04 / 2220: 40$ & $41.22-114.81$ & 7.7 & 4.4 & 3.83 & 3.97 & 4.16 & 4.08 & 4.10 \\
\hline
\end{tabular}

Table 3. Source data for select nuclear tests at the Nevada Test Site. All information from nuclear tests is taken from Springer et al. (2002). Information on the chemical and nuclear equivalent yield of the NPE is taken from Denny (1994) and Rohrer (1994), respectively.

\begin{tabular}{|l|l|l|l|l|l|l|}
\hline Name & $\begin{array}{l}\text { Date } \\
\text { yyyy/mm/dd }\end{array}$ & $\begin{array}{l}\text { Epicenter } \\
\text { Lat. Long. }\end{array}$ & $\begin{array}{l}\text { Depth } \\
(\mathrm{m})\end{array}$ & Yield (kt) & Medium & Location \\
\hline Hearts & $1979 / 09 / 06$ & $37.088-116.054$ & 640 & 140 & Tuff & Yucca \\
\hline Jomada & $1982 / 01 / 28$ & $37.091-116.052$ & 639 & 139 & Tuff & Yucca \\
\hline Atrisco & $1982 / 08 / 05$ & $37.084-116.007$ & 640 & 138 & Tuff & Yucca \\
\hline Chancellor & $1983 / 09 / 01$ & $37.273-116.356$ & 624 & 143 & Rhyolite & Pahute Mesa \\
\hline Glencoe & $1986 / 03 / 22$ & $37.083-116.067$ & 610 & 29 & Tuff & Yucca \\
\hline Cybar & $1986 / 07 / 17$ & $37.279-116.356$ & 627 & 119 & Rhyolite & Pahute Mesa \\
\hline NPE & $1993 / 09 / 22$ & $37.017-116.210$ & 390 & $1.07(1.9)$ & Tuff & Pahute Mesa \\
\hline
\end{tabular}




\section{Topographic Map}

Figure 1

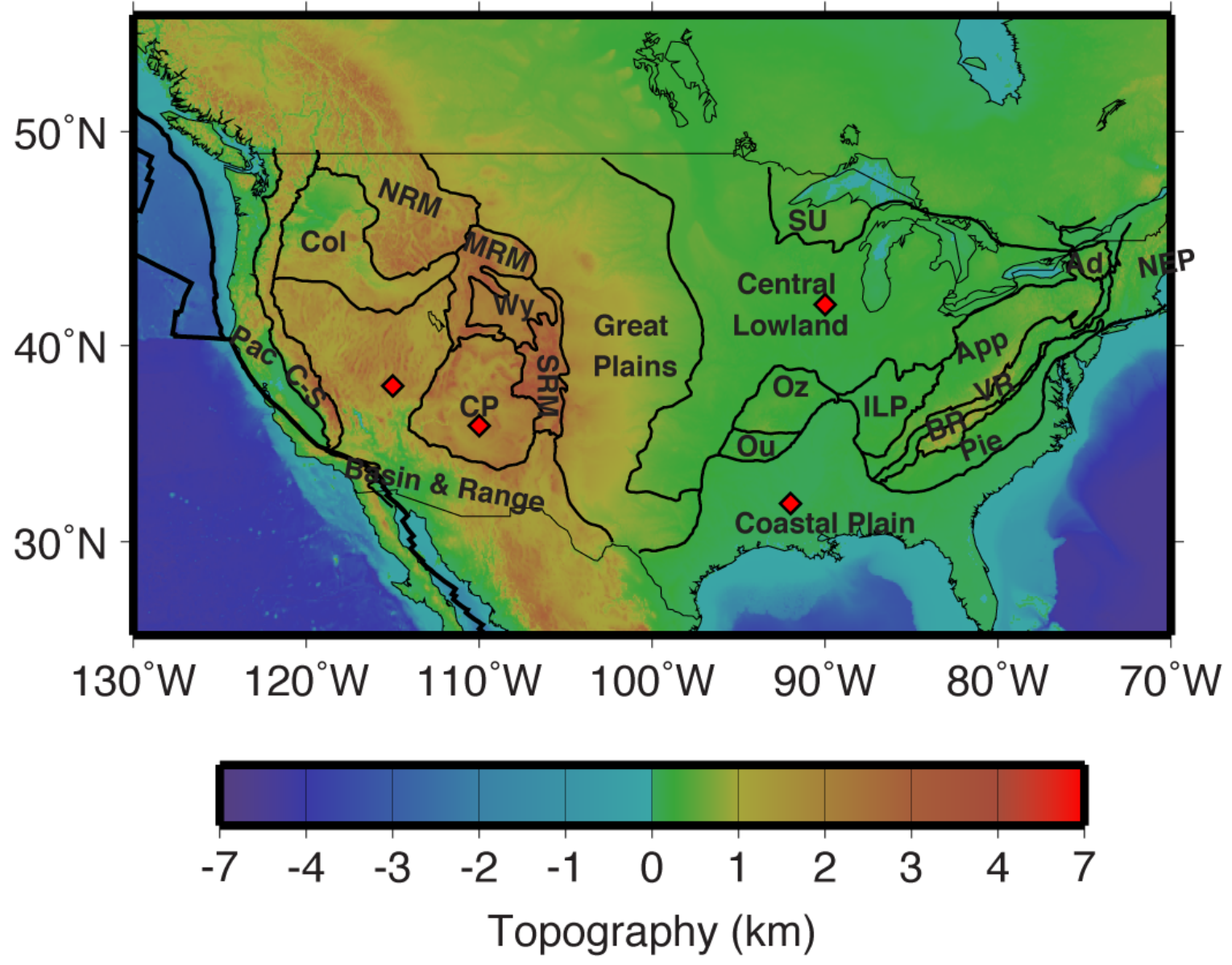


Figure 2
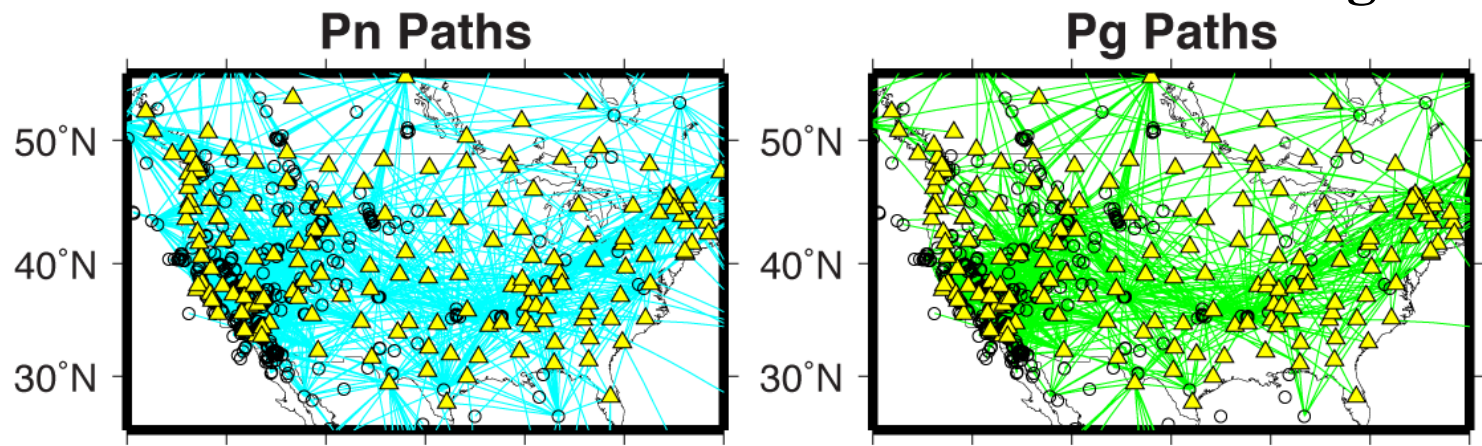

$130^{\circ} \mathrm{W} 20^{\circ} \mathrm{W} 10^{\circ} \mathrm{W} 00^{\circ} \mathrm{W} 90^{\circ} \mathrm{W} 80^{\circ} \mathrm{W} 70^{\circ} \mathrm{W} \quad 130^{\circ} \mathrm{W} 20^{\circ} \mathrm{W} 10^{\circ} \mathrm{W} 00^{\circ} \mathrm{W} 90^{\circ} \mathrm{W} 80^{\circ} \mathrm{W} 70^{\circ} \mathrm{W}$
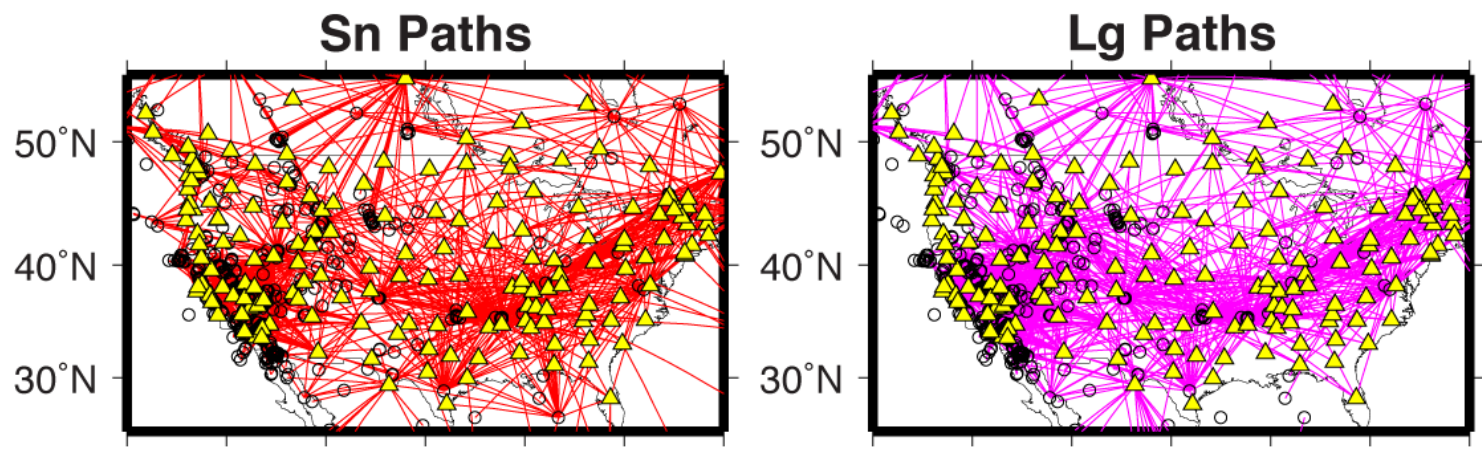

$130^{\circ} \mathrm{W} 20^{\circ} \mathrm{W} 10^{\circ} \mathrm{W} 00^{\circ} \mathrm{W} 90^{\circ} \mathrm{W} 80^{\circ} \mathrm{W} 70^{\circ} \mathrm{W}$

$130^{\circ} \mathrm{W} 20^{\circ} \mathrm{W} 10^{\circ} \mathrm{W} 00^{\circ} \mathrm{W} 90^{\circ} \mathrm{W} 80^{\circ} \mathrm{W} 70^{\circ} \mathrm{W}$ 


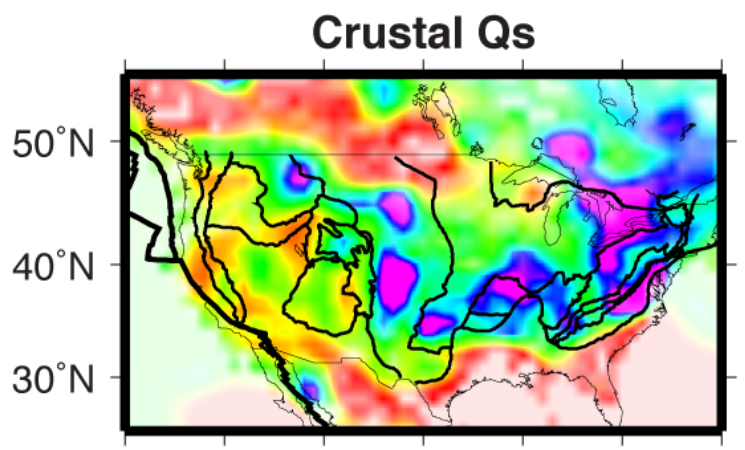

$130^{\circ} \mathrm{W} 20^{\circ} \mathrm{W} 10^{\circ} \mathrm{W} 00^{\circ} \mathrm{W} 90^{\circ} \mathrm{W} 80^{\circ} \mathrm{W} 70^{\circ} \mathrm{W}$

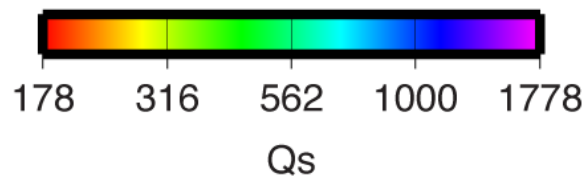

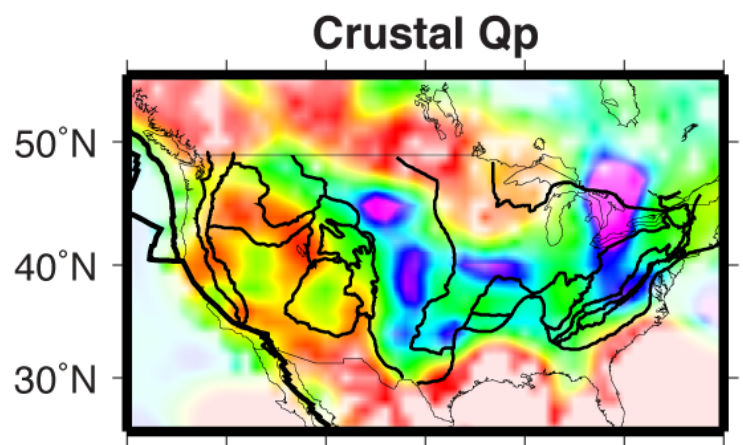

$130^{\circ} \mathrm{W} 20^{\circ} \mathrm{W} 10^{\circ} \mathrm{W} 00^{\circ} \mathrm{W} 90^{\circ} \mathrm{W} 80^{\circ} \mathrm{W} 70^{\circ} \mathrm{W}$

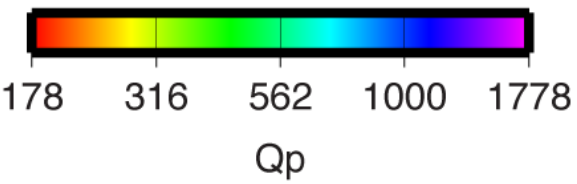

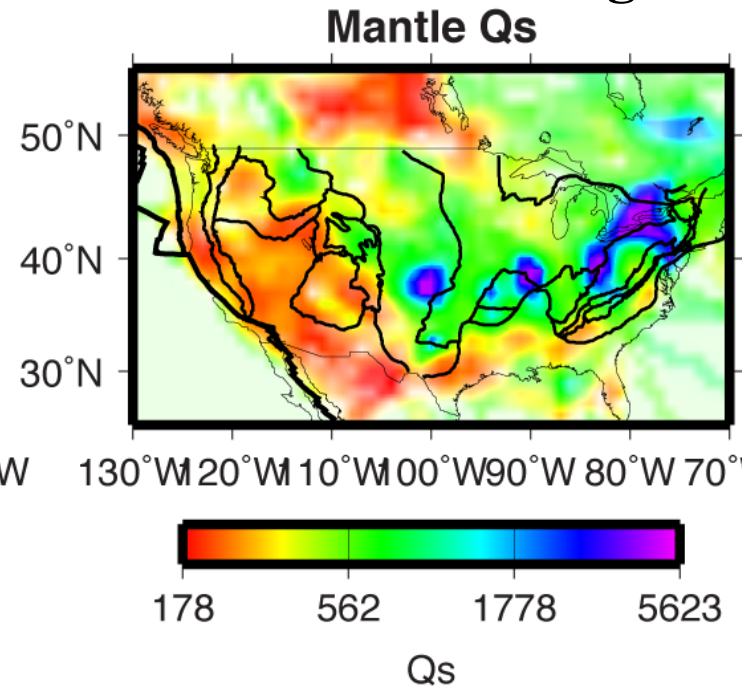

$130^{\circ} \mathrm{W} 20^{\circ} \mathrm{W} 10^{\circ} \mathrm{W} 00^{\circ} \mathrm{W} 90^{\circ} \mathrm{W} 80^{\circ} \mathrm{W} 70^{\circ} \mathrm{W}$

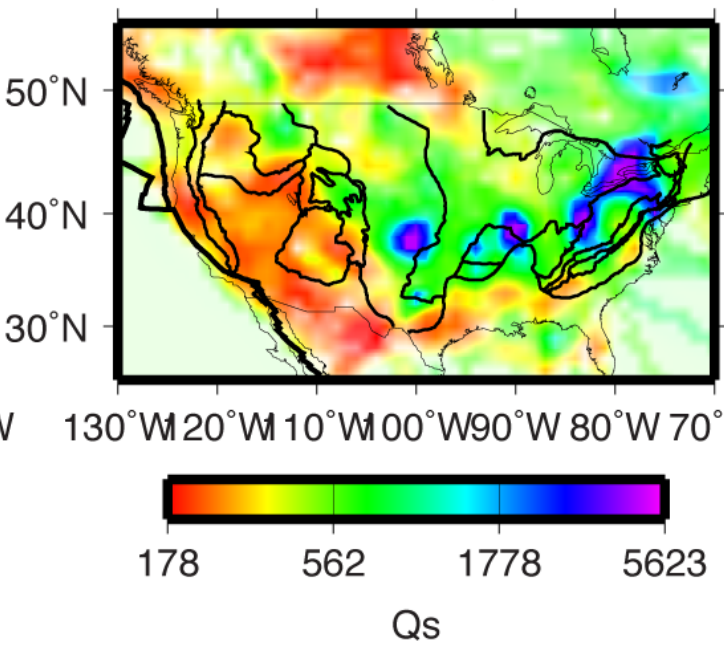

Figure 3

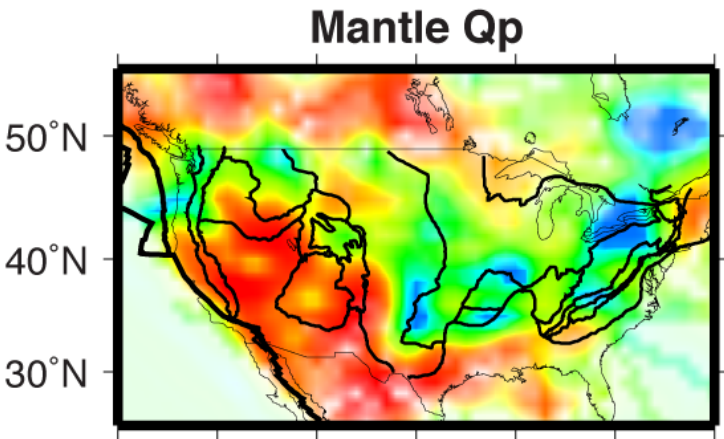

$130^{\circ} \mathrm{W} 20^{\circ} \mathrm{W} 10^{\circ} \mathrm{W} 00^{\circ} \mathrm{W} 90^{\circ} \mathrm{W} 80^{\circ} \mathrm{W} 70^{\circ} \mathrm{W}$

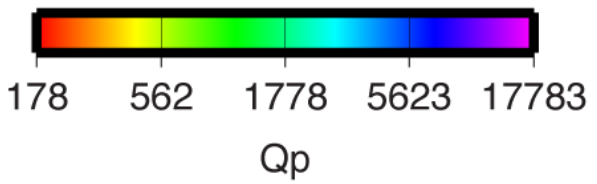


Figure 4
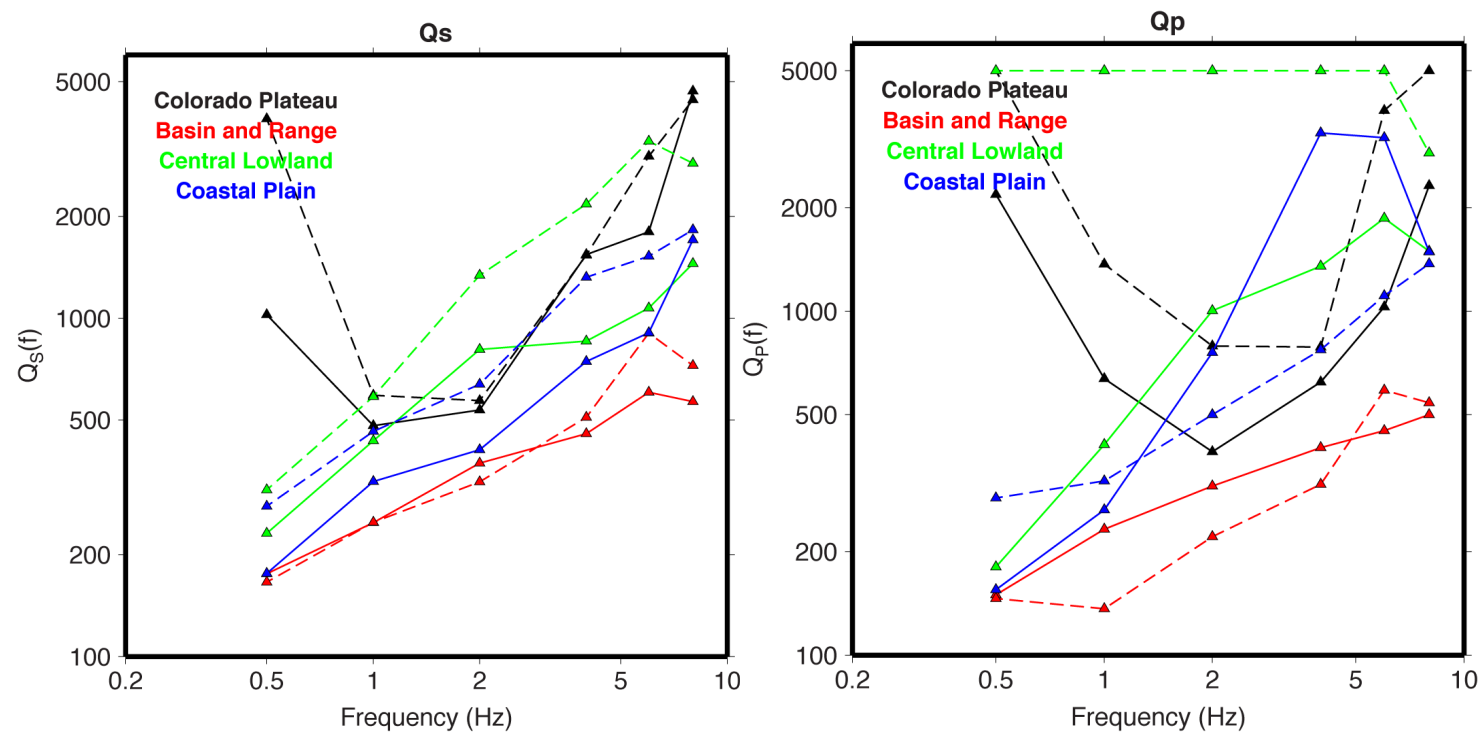
Figure 5

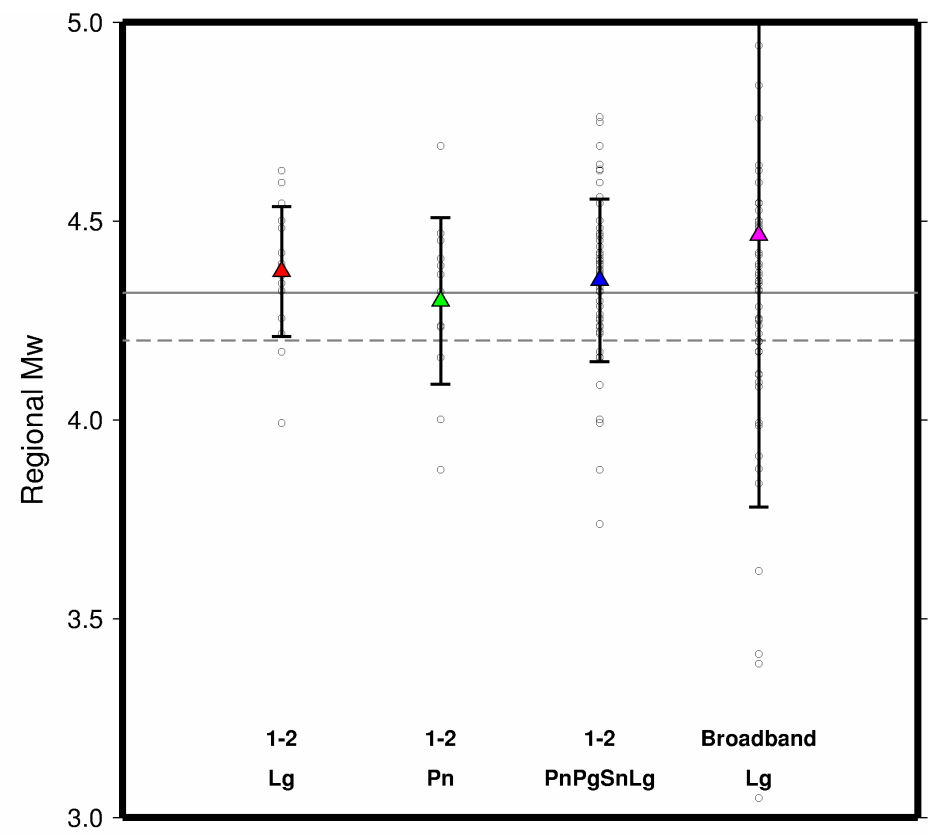

Magnitude Method

Wells, NV Sequence

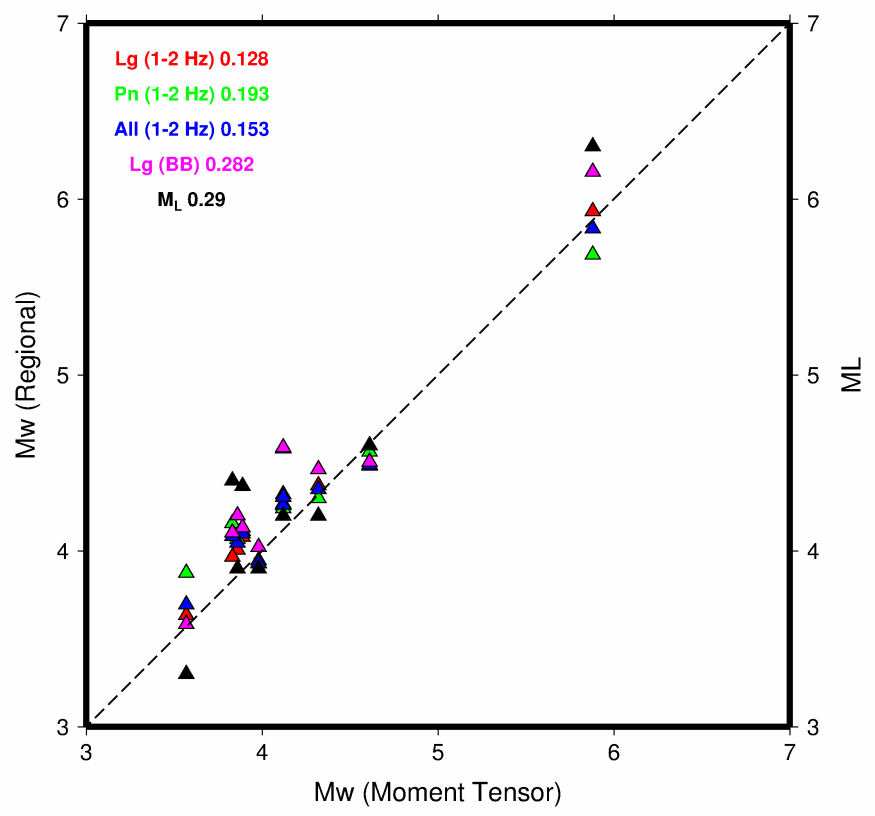


Figure 6
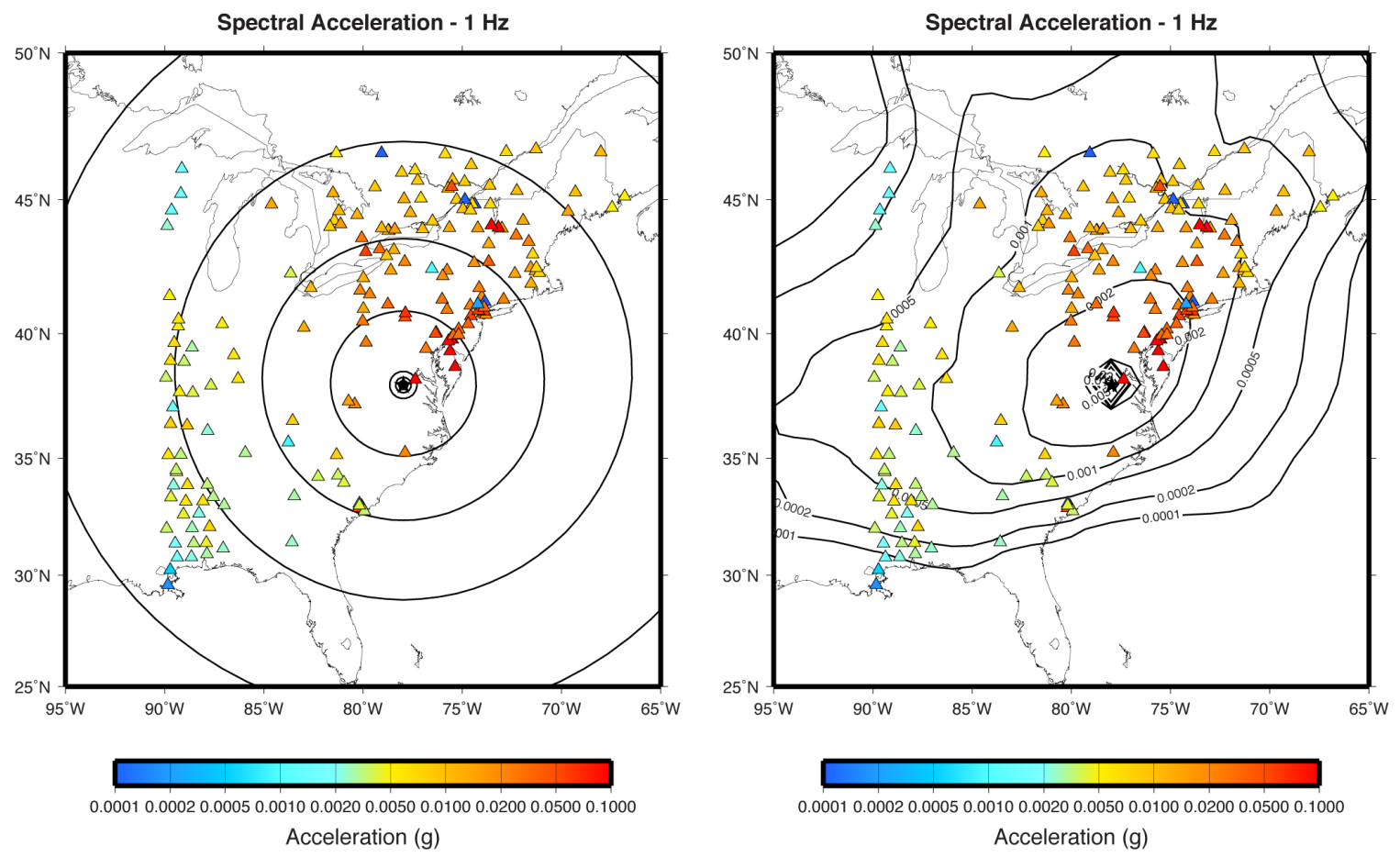
Figure 7

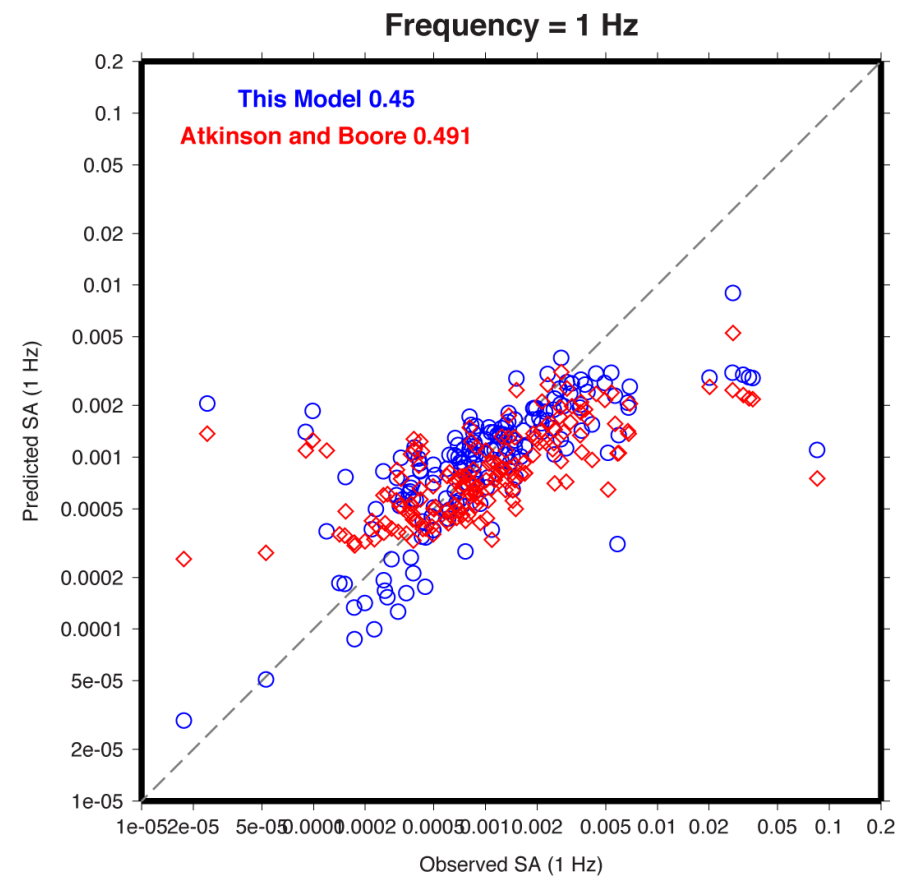


Figure 8

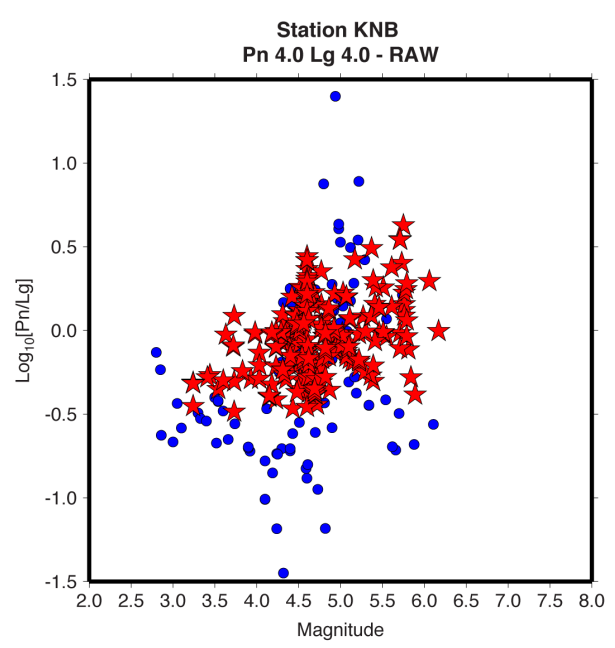

Pn 4.0 Lg 4.0 - RAW

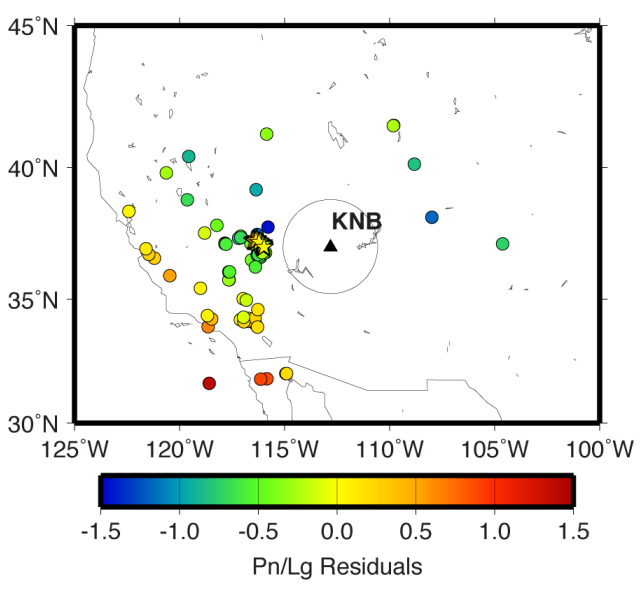

Station KNB

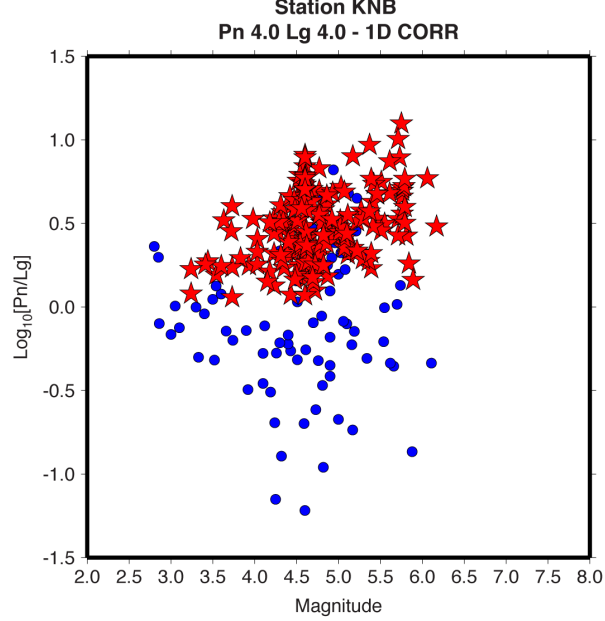

Pn 4.0 Lg 4.0 - 1D CORR

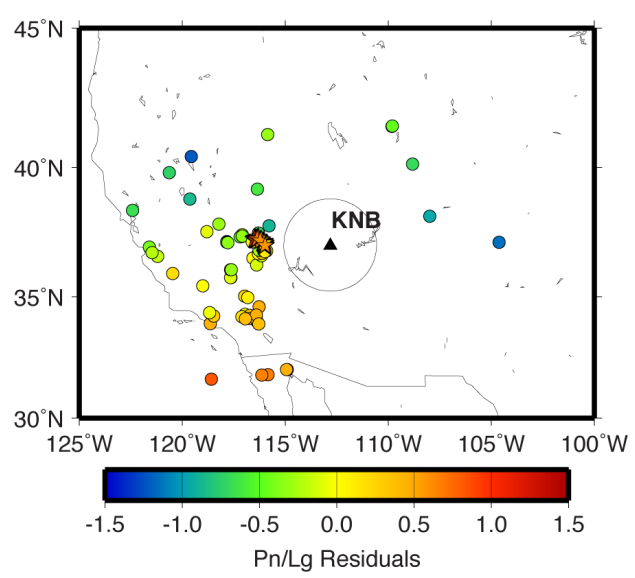

Station KNB

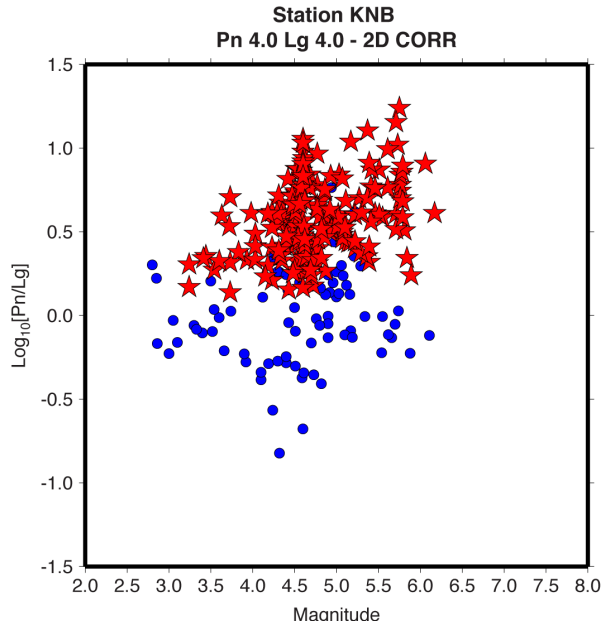

Pn 4.0 Lg 4.0 - 2D CORR

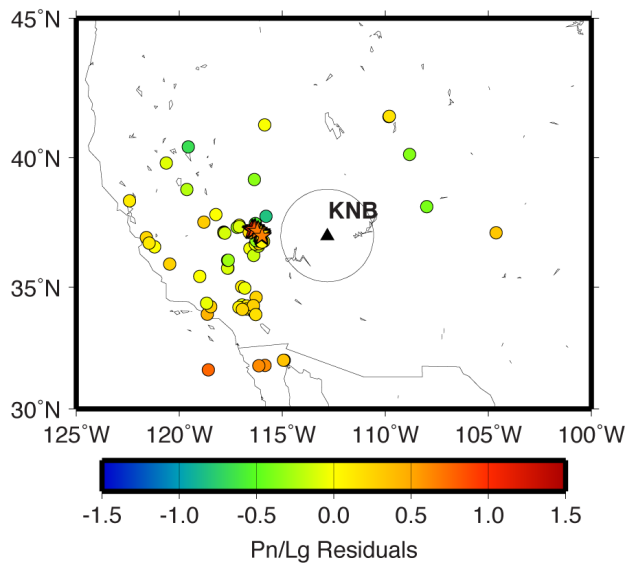


Figure 9

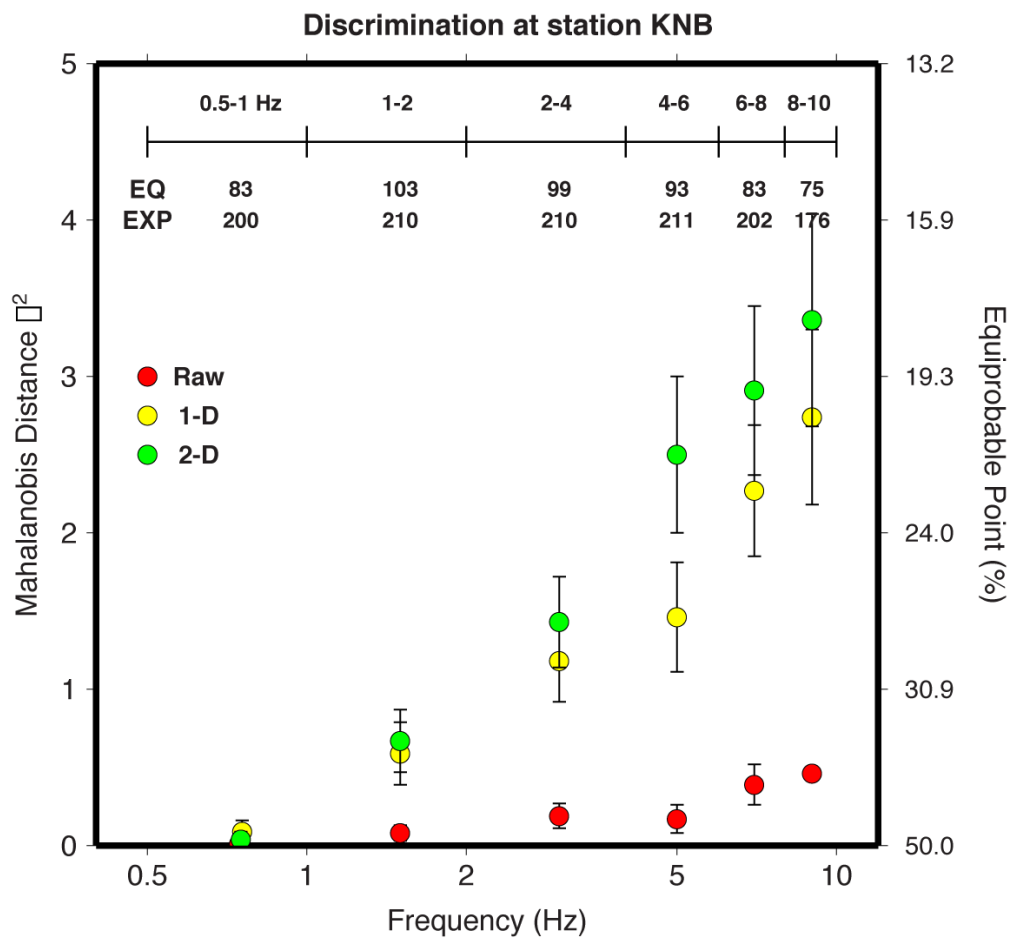


Figure 10

a)

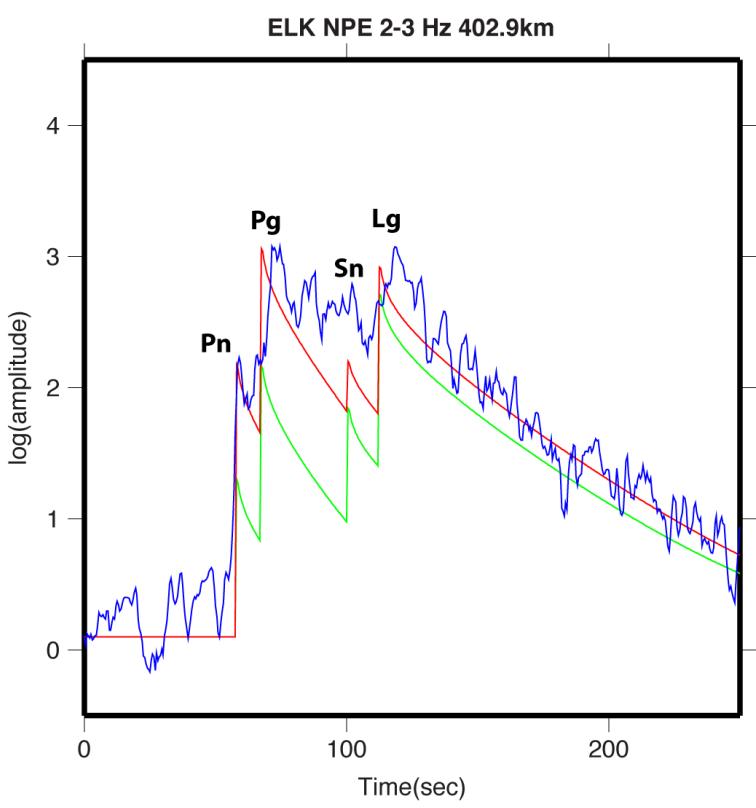

b)

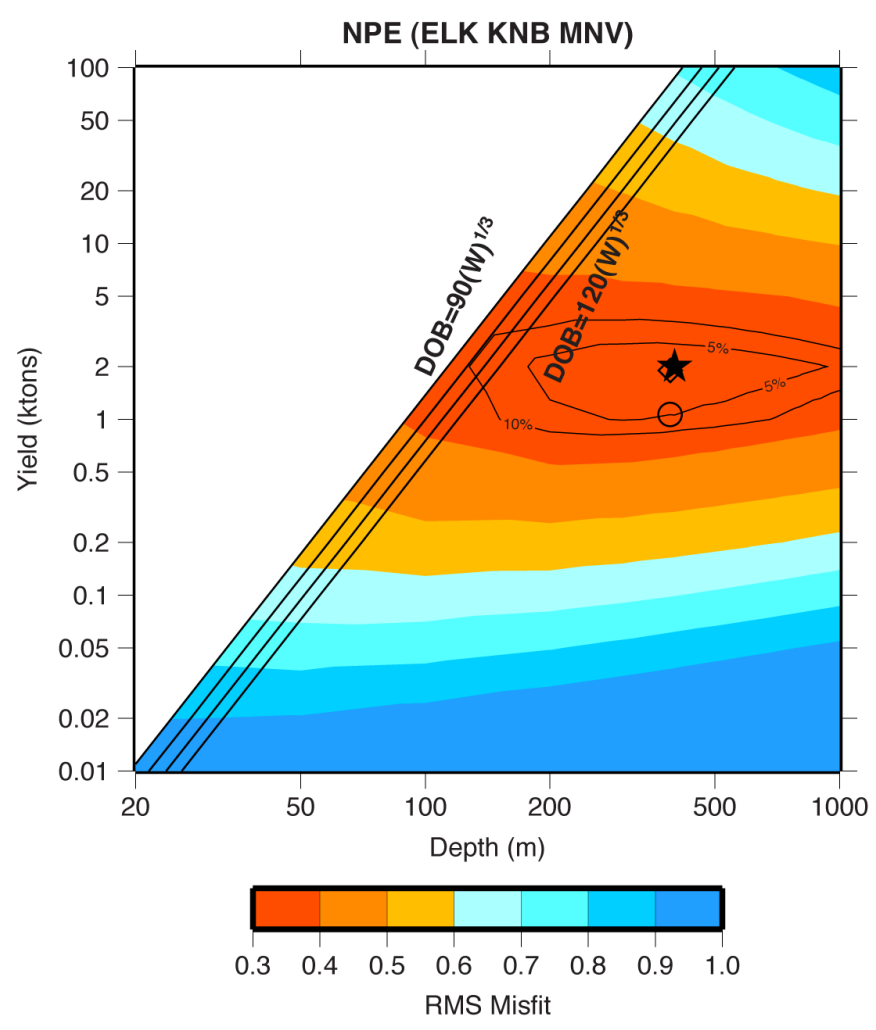


Figure 11
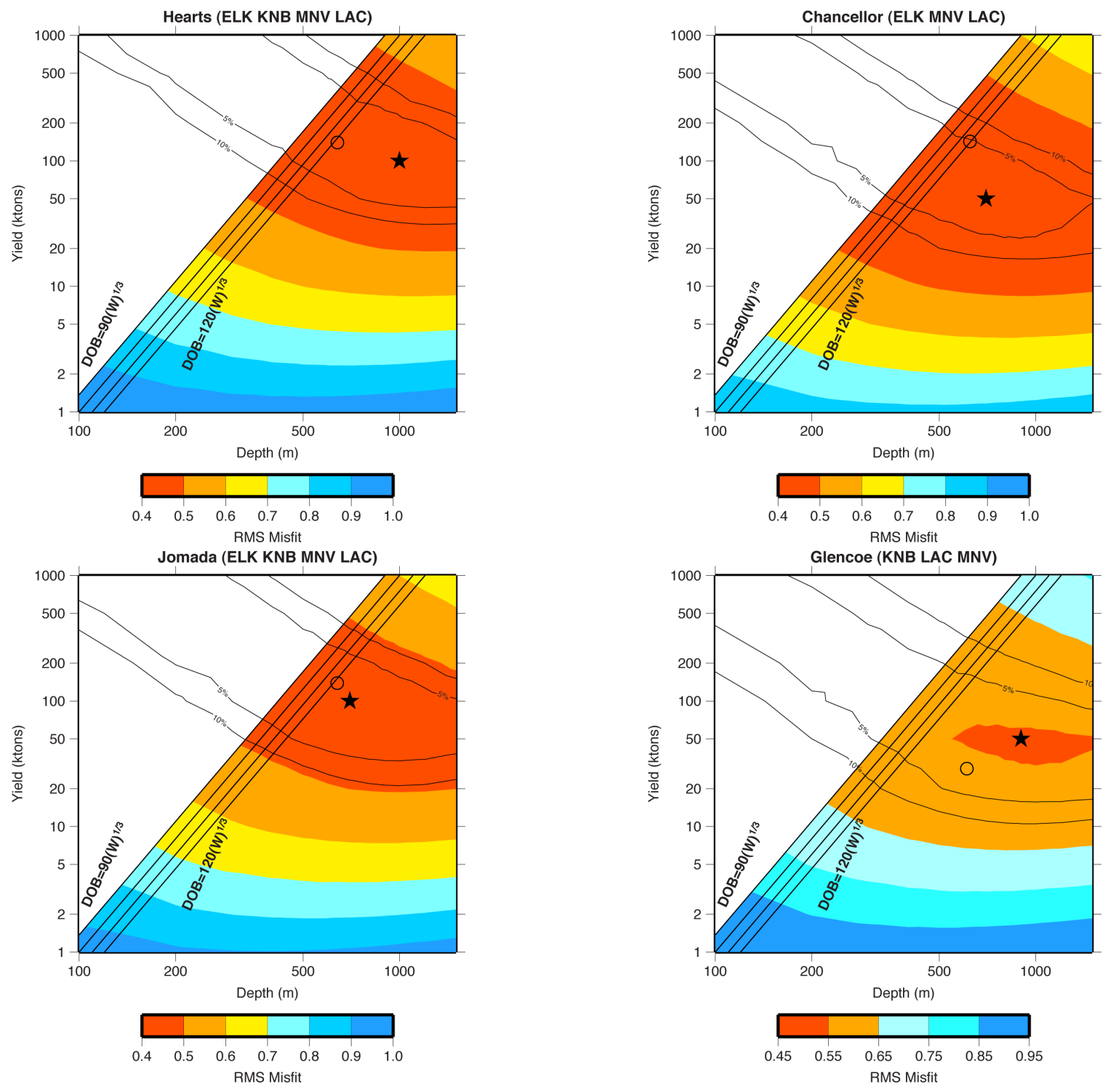


\section{Figure 11 (cont.)}
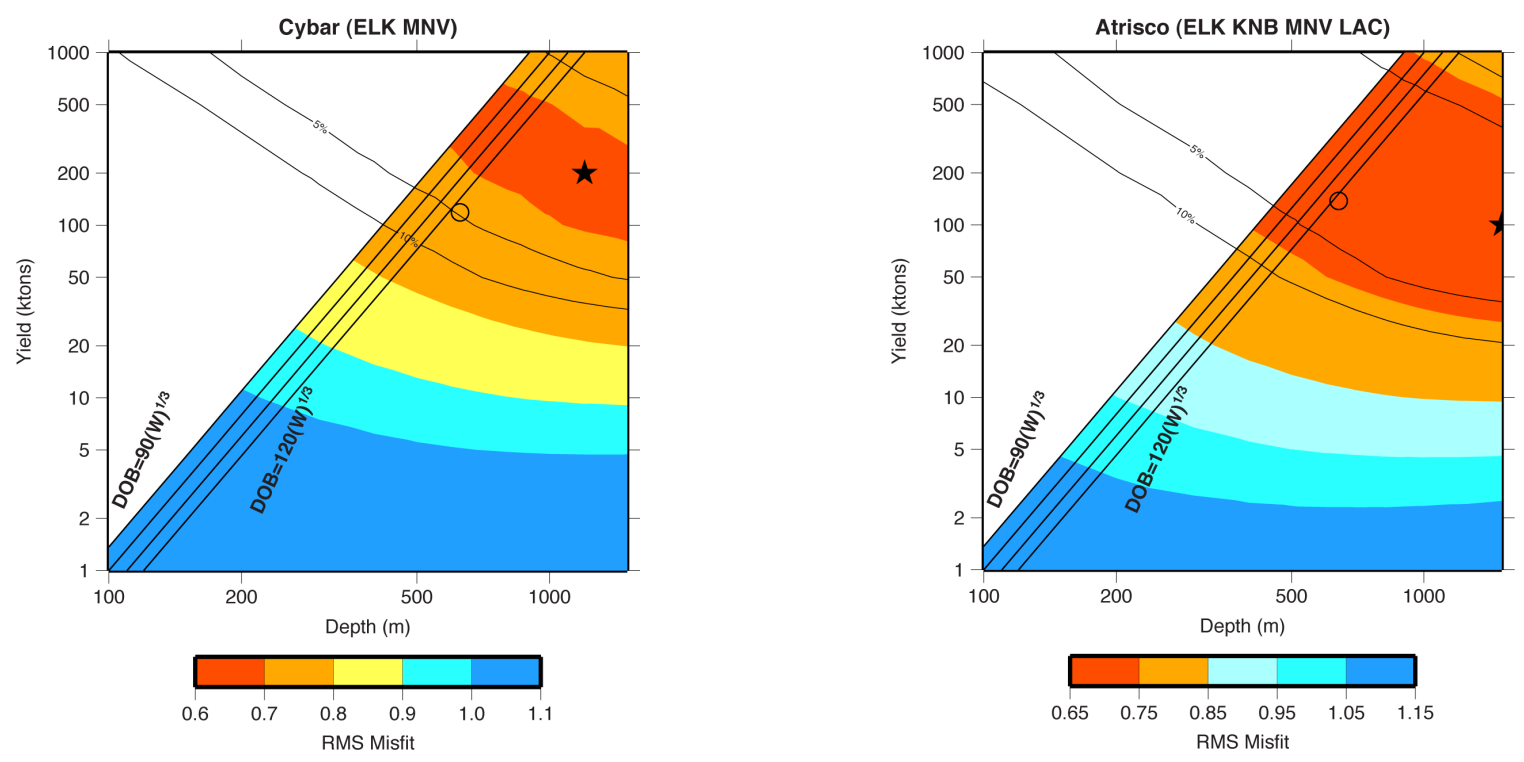